\section{Marcela Peres Castilho-Pelloso}

Dina Lúcia Morais Falavigna

Ana Lúcia Falavigna-Guilherme

\title{
Suspected acute toxoplasmosis in pregnant women
}

\section{Suspeita de toxoplasmose aguda em gestantes}

\begin{abstract}
OBJECTIVE: To determine the prevalence of reagent serology for suspected acute toxoplasmosis in pregnant women and to describe clinical, laboratory and therapeutic profiles of mothers and their children.

METHODS: A retrospective study was conducted with IgM-anti-Toxoplasma gondiireagent pregnant women and their children who attended the public health system in the state of Paraná, Southern Brazil, from January 2001 to December 2003. Information were obtained from clinical, laboratory (ELISA $\operatorname{IgM} / \operatorname{IgG}$ ) and ultrasonographic data and from interviews with the mothers. To test the homogeneity of the IgM indices in relation to the treatment used, the Pearson's Chi-square test was applied. Comparisons were considered significant at a 5\% level.
\end{abstract}

RESULTS: Two hundred and ninety (1.0\%) cases of suspected IgM-reagent infection were documented, with a prevalence of 10.7 IgM-reagent women per 1,000 births. Prenatal care started within the first 12 weeks for 214/290; 146/204 were asymptomatic. Frequent complaints included headaches, visual disturbance and myalgia. Ultrasonography revealed abnormalities in 13 of 204 pregnancies. Chemoprophylaxis was administered to 112/227; a single ELISA test supported most decisions to begin treatment. Pregnant women with IgM indices $=2.000$ tended to be treated more often. Among exposed children, 44/208 were serologically followed up and all were IgGreagent, and three IgM-reagent cases showed clinical symptoms.

CONCLUSIONS: The existence of pregnant women with laboratorially suspected acute toxoplasmosis who were not properly followed up, and of fetuses that were not adequately monitored, shows that basic aspects of the prenatal care are not being systematically observed. There is need of implementing a surveillance system of pregnant women and their children exposed to T. gondii.

KEYWORDS: Pregnant women. Toxoplasmosis, epidemiology. Toxoplasmosis, congenital, prevention \& control. Toxoplasmosis, congenital, diagnosis. Prenatal care. Seroepidemiological studies. Epidemiological surveillance services.

\section{RESUMO}

Universidade Estadual de Maringá. Maringá, PR, Brasil

\author{
Correspondence: \\ Marcela Castilho Peres-Pelloso \\ Programa de Pós-Graduação em Ciências da \\ Saúde - Bloco 126 \\ Av. Colombo, 5790 Vila 7 Campus da \\ Universidade Estadual de Maringá \\ 87020-090 Maringá, PR, Brasil \\ E-mail: cellacpp@yahoo.com.br
}

Approved: 9/12/2006
OBJETIVO: Determinar a prevalência de gestantes com sorologia reagente suspeita
de toxoplasmose aguda e descrever as variáveis maternas e do concepto relacionadas
ao perfil clínico, laboratorial e terapêutico. MÉTODOS: Estudo retrospectivo com gestantes IgM anti-Toxoplasma gondii reagentes e conceptos atendidos em serviço público de saúde do Paraná, de janeiro/ 2001-dezembro/2003. Foram obtidas informações a partir de dados dos registros clínicos, laboratoriais (ELISA IgM/IgG), ultrassonográficos e de entrevista materna. 
Para testar a homogeneidade dos indices de $\operatorname{IgM}$ em relação ao tratamento usado, aplicou-se o qui-quadrado de Pearson. O nível de significância adotado foi de 5\%.

RESULTADOS: Ocorreram 290 casos (1,0\%) IgM reagentes, evidenciando prevalência de 10,7 gestantes com sorologia reagente a cada 1.000 nascimentos. Duzentos e quatorze de 290 gestantes iniciaram o pré-natal até a 12a semana de gestação; 146/ 204 foram assintomáticas; cefaléia, distúrbios visuais e mialgia foram queixas freqüentes; 13/204 gestantes apresentaram anormalidades ao ultrassom; 112/227 gestantes receberam quimioprofilaxia; um único teste ELISA apoiou a maioria das tomadas de decisão para a quimioprofilaxia. Houve tendência em tratar gestantes com índices de $\operatorname{IgM}=2.000$. Dentre as crianças expostas, 44/208 tiveram algum acompanhamento sorológico, das quais todas foram $\mathrm{IgG}$ reagentes e três casos $\operatorname{IgM}$ reagentes apresentaram manifestações clínicas.

CONCLUSÕES: A existência de gestantes com suspeita laboratorial de toxoplasmose aguda não devidamente investigada e de conceptos sem monitoração adequada evidenciam que aspectos fundamentais da assistência pré-natal não estão sendo sistematicamente observados. Aponta-se a necessidade de implementar o sistema de vigilância para gestantes e crianças expostas ao T. gondii.

DESCRITORES: Gestantes. Toxoplasmose, epidemiologia. Toxoplasmose congênita, prevenção e controle. Toxoplasmose congênita, diagnóstico. Cuidado pré-natal. Estudos soroepidemiológicos. Serviços de vigilância epidemiológica.

\section{INTRODUCTION}

Toxoplasmosis is a widespread zoonosis caused by the intracellular parasite Toxoplasma gondii, which affects up to one-third of the world's population. This disease can produce a wide range of clinical manifestations or, in most cases, progress asymptomatically. ${ }^{14}$ Primary infection during gestation may cause serious neurological damage, blindness and even fetal death. ${ }^{15,22}$

The chances of fetal infection by $T$. gondii increase with the stage of pregnancy, from $5-15 \%$ in the first half of gestation, to $60-80 \%$ in the second half. Conversely, the chances of serious lesions and death decrease, declining from $70-80 \%$ in the first half to less than $10 \%$ in the second half. ${ }^{3}$ Anti-parasite treatment of pregnant women can reduce the risk of transmission to or consequences for the fetus if it is started early. ${ }^{14,22}$

An important aspect of this disease is the possibility of reagudization in any phase of life. Tissue damage can begin during pregnancy and sometimes continues after birth, during infancy, or later in adulthood, causing neuropsychomotor and optical sequelae., ${ }^{711,15}$

Because of the persistence of certain classes of antibodies, such as IgM and IgA, and the high sensitivity of the serological methods currently available, complementary tests are necessary in order to assess more accurately the chronology of the infection in preg- nant women. ${ }^{8}$ However, the risk of congenital transmission may exist not only in cases of seroconversion, but also in cases of suspected infection as detected by elevated mean titers of IgM and/or IgA and $\mathrm{IgG}^{2,10}$ Therefore, clinical and serological follow-up for all neonates of IgM-reagent pregnant women, even if they are asymptomatic, is recommended..$^{15,18}$

Brazil is a vast country, with marked differences in socioeconomic conditions and health care levels among its population. The performance of programs for control of congenital toxoplasmosis in different regions of the country must be assessed. ${ }^{17}$ In the state of Paraná, Southern Brazil, IgG anti-T. gondii prevalence ranged from $40 \%{ }^{4}$ to $66 \%{ }^{5}$ in 1983 e 1996 respectively, and $1.8 \%$ IgM anti-T. gondii seroincidence in pregnant women has been observed in northern areas of the state. ${ }^{13}$

Based on routine laboratory tests during prenatal care, the objective of the present study was to verify the prevalence of suspected reagent serology for acute toxoplasmosis among pregnant women, and to describe the clinical, laboratory and therapeutic profiles of mothers and children suspected to have been exposed during gestation.

\section{METHODS}

An observational, longitudinal and retrospective study with a dynamic population base, consisting of preg- 
nant women with suspected acute toxoplasmosis and their exposed children, was carried out. These women and their children attended the public health care services in the northwestern macro-region of the state of Paraná (Figure), from January 2001 to December 2003. The inclusion criteria were IgM anti- $T$. gondii pregnant women in any gestational trimester and children born from these reagent mothers.

Information about the pregnant women and their children was gathered from data available in the public health care laboratory network, medical records, the Prenatal Information System (SISPrenatal) database, the register of pregnant women cared for by the Family Health Program (PSF), the Sistema Nacional de Informação de Nascidos Vivos (SINASC - National Live Birth Information System) database, and the Sistema Nacional de Informação sobre Mortalidade (SIM National Mortality System). These data were complemented by interviews. A pre-coded structured questionnaire was used, collecting data on the residence of the women, prenatal care (obstetric history, date of admission), signs of maternal infection by $T$. gondii (clinical, laboratory, ultrasonographic abnormalities and treatment) and data on the newborns (date of birth/death, weight, gestational age, clinical and laboratory findings, care and treatment).

The diagnostic protocol* for toxoplasmosis in pregnant women in the state of Paraná was assessed by the ELISA technique for IgM and $\operatorname{IgG}$ detection during the first trimester of pregnancy, preferably; it is suggested to confirm IgM positivity by assessing IgA. Repeating the IgM and IgG in the second and third trimesters was recommended for non-reagent pregnant women. The avidity test was not used by the studied public health care services. In 2004, the State Protocol for high-risk pregnancies was revised, ${ }^{* *}$ and in cases of IgM reagents, IgA serology was replaced by the $\operatorname{IgG}$ avidity test to confirm uncertain cases. The therapeutic plan assumes that there is maternalfetal risk of congenital transmission*,** when IgG and IgM are reagents and the avidity is low. Although laboratory diagnosis and treatment are provided by the state, they were not always available.

The laboratory diagnostic method used for pregnant women and their children was the Microparticle En-

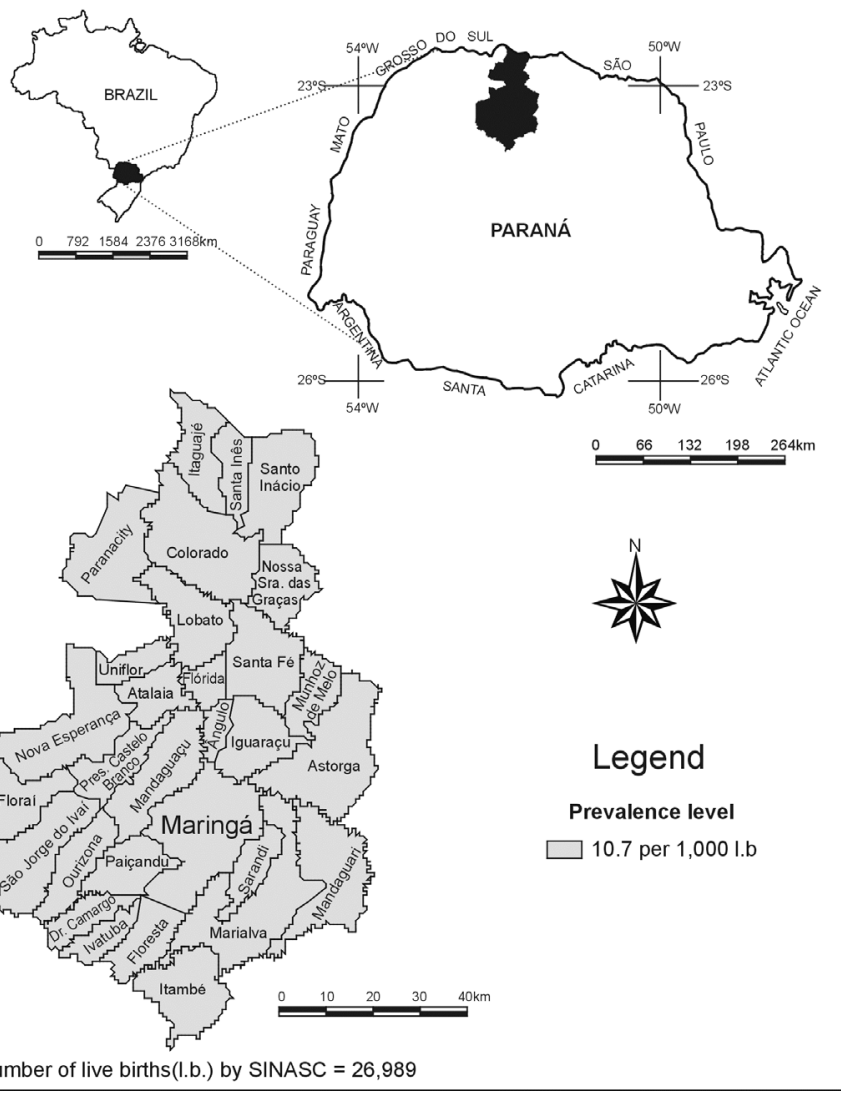

igure - Geographic location and administrative divisions of the municipalities included in the study, and mean prevalence of anti- $T$. gondii IgM in resident pregnant women. State of Paraná, Southern Brazil, anuary 2001 to December 2003.

zyme Immunoassay (MEIA) for anti-T. gondii IgM and IgG (Abbot Diagnostics AxSYM ${ }^{\circledR}$ ). IgM indices over 0.600 and $\mathrm{IgG}$ values over $3.0 \mathrm{IU} / \mathrm{mL}$ were considered as reagent.

The prevalence of pregnant women anti- $T$. gondiiIgM-reagent accumulated in the period was calculated from the number of live births recorded in SINASC. Cases of congenital toxoplasmosis were considered to be those newborns with anti-T. gondiiIgM reagent serology, and those who showed seroconversion during the first year of life, regardless of clinical manifestations. Suspected cases of congenital toxoplasmosis were those newborns of anti- $T$. gondii-IgM-reagent mothers with visual disturbances, abnormalities of neuropsychomotor development, and other nonspecific neurological manifestations without diagnostic confirmation.

The EPI-Data software program version 3.0 was used for database entry, and the SAS software program version 8.2 was used in the result analyses. To test the homogeneity of the IgM indices in relation to the

*Secretaria de Estado da Saúde do Paraná. Protocolo de gestação de alto risco. 2a ed. Curitiba: SESA; 2002.

**Secretaria de Estado da Saúde do Paraná. Protocolo de gestação de alto risco. 3a ed. Curitiba: SESA; 2004. 
treatment provided, the Pearson's Chi-square test was applied. Comparisons were considered significant at a $5 \%$ significance level.

The study was approved by the Research Ethics Committee of the Universidade Estadual de Maringá (COPEP Resolution 196/960).

\section{RESULTS}

Of 318 pregnant women with laboratory tests indicating acute toxoplasmosis, 290 met the inclusion criteria, representing $1.0 \%$ of 29,868 pregnancies estimated by SISPrenatal during the study period. The prevalence of IgM-anti-T. gondii reagent was 10.7 per 1,000 live births by SINASC (Figure).

Among these women, 214 (73.9\%) had started followup by the $12^{\text {th }}$ week of pregnancy, and $96(26.1 \%)$ between the $13^{\text {th }}$ and $32^{\text {nd }}$ week. The mean interval between admission and sampling for the first serology test in the 290 pregnant women was 17.7 days; for 108 $(37.2 \%)$ of them it took between zero to seven days, for 98 (33.8\%) between eight and 30 days, and for 84 $(29.0 \%)$ it was collected after more than a month. For $258(89 \%)$ pregnant women with prenatal information, more than a month had elapsed between delivery of the laboratory result and beginning of medical care. The mean gestational age during collection of the first blood sample was $11.36 \pm 6.09$ weeks.

Of 16,686 samples collected for the initial assessment of anti-T. gondii IgM and IgG, 26 were IgMreagent, 264 IgM- and IgG-reagent, 10,882 IgG-reagent and 5,740 non-reagent. Among the 290 IgMreagent pregnant women, a two-sample serological follow-up for IgM was carried out in 90 (31\%); and in $38(13.1 \%)$ of them a three-sample follow-up was carried out. The majority, 76/90 (84\%) and 26/38 (68\%) respectively, remained anti- $T$. gondii-IgM reagent in the subsequent samples. The median $(0.783 ; 0.861$ and 0.726$)$ and mean $(1.130 ; 1.130$ and 0.980$)$ of the three IgM sample indices were very close. None of the women studied underwent a laboratory test for IgA, and no amniotic liquid was tested for fetal infection by PCR and for inoculation into mice.

The anti- $T$. gondii-IgG avidity test was performed in only ten cases (3.4\%). Two cases showed low avidity, one in the third month and the other in the sixth month of pregnancy, suggesting acute infection. Both of them were treated with spiramycin. Three cases showed high avidity, suggesting chronic infection, and five cases showed inconclusive results.

Clinical and ultrasonographic data were available for
204 of the 290 women (70.3\%). Of these, 146 (71.6\%) were asymptomatic. Among women with clinical manifestations, the main complaints were intense frontal or periorbital headaches in $58(28.4 \%)$ cases. There were concomitant symptoms in $45(22.0 \%)$ cases, who also presented scotomatous visual disturbance, 35 (17.1\%) with myalgia, and 24 (11.8\%) with fever accompanied by adenomegaly. The ultrasonographies, performed after the $23^{\text {rd }}$ week of pregnancy in 141 cases $(69 \%)$, revealed alterations in 13 cases $(6.4 \%)$. The alterations detected were oligohydramnios (5 cases), polyhydramnios (2), placental alterations (2), fetal cardiac arrhythmia (1), anencephaly (1), alterations in the cranium (1) and renal malformations (1). In six of 13 cases that progressed to fetal loss, congenital T. gondii infection was not confirmed by serology; however, in four cases, anatomical-pathological examination revealed multivisceral autolysis or fetal malformation suggestive of toxoplasmosis. Spiramycin was taken by seven women with ultrasonographic abnormalities (53.8\%). Three pregnancies continued to term but were stillborn. Among the four live births, there were optical alterations, cardiac arrhythmia and renal alterations, and two had no apparent sequelae.

Information on treatment provided was available for $227(78.3 \%)$ of the 290 women: 112 (49.3\%) were prescribed chemoprophylaxis with different therapeutic regimens, and 115 (39.7\%) were not treated (Table 1). In 27 cases (24.1\%), the time elapsed between sampling for the first serological test and starting treatment was less than 15 days; in 31 cases (27.7\%), the elapsed time was 15 to 30 days; and in 54 cases $(48.2 \%)$, it was more than one month. The prescribed therapy was administered until the end of gestation in $64(57.1 \%)$ of the 112 women treated. Side effects were reported by 27 (24.1\%) of them, with the most frequent complaints related to the gastrointestinal tract. The prescription of chemoprophylaxis varied in relation to the initial levels of IgM (Table 2). Women with IgM indices higher than 2.000 were treated more frequently than those with indices between 0.600 and 1.000 (Table 2).

Table 1 - Therapeutic regimens used by anti-T. gondii-IgMreagent pregnant women. State of Paraná, Southern Brazil, January 2001 to December 2003.

\begin{tabular}{lcc}
\hline Therapeutic regimen & \multicolumn{2}{c}{ Pregnant } \\
& $\mathrm{N}$ & women \\
\hline Triple scheme $\mathrm{Sp}^{1}$ intercalated $\mathrm{S}^{2}+\mathrm{P}^{3}+\mathrm{FA}^{4}$ & 4 & 1.4 \\
Spiramycin with a 1-week suspension & 41 & 14.1 \\
Spiramycin with a 2-week suspension & 48 & 16.5 \\
Spiramycin continuously & 19 & 6.5 \\
No treatment prescribed & 115 & 39.7 \\
Treatment unknown & 63 & 21.8 \\
\hline Total & 290 & 100.0 \\
\hline
\end{tabular}

1. Spiramycin; 2. Sulfadiazine; 3. Pyrimethamine; 4. Folinic Acid 
Table 2 - Anti-T. gondii indices compared to treatment. State of Paraná, Southern Brazil, January 2001 to December 2003.

\begin{tabular}{lccc}
\hline Anti-T. gondii IgM & \multicolumn{2}{c}{ Treatment } & Total \\
& Yes & No & \\
\hline 0.600 to 1.000 & 63 & 86 & 149 \\
1.000 to 2.000 & 32 & 23 & 55 \\
Greater than 2.000* & 17 & 6 & 23 \\
\hline Total & 112 & 115 & 227 \\
\hline $\mathrm{p}=0.0095$ & & &
\end{tabular}

Information on 232 newborns showed that $29(12.5 \%)$ were premature, $23(9.9 \%)$ were underweight and 180 $(77.6 \%)$ were normal weight. There were 16 cases $(6.9 \%)$ of fetal loss through miscarriages and stillbirths, with 5 (31\%) showing malformations (anencephaly, agenesis of the limbs, hydrocephalus). Based on the 26,989 births from SINASC and death records from SIM, the mortality rate among children (live births and fetal losses) of IgM-reagent mothers was 0.7 per 1,000 live births.

Of 208 exposed children who could be located during the first year after birth, 194 (93\%) were evaluated in a pediatric or general clinic, and 55 (26.4\%) were referred to specialty treatment (infectious diseases, ophthalmology or neurology). Serological examinations were performed in $44(21.1 \%)$ children, all anti- $T$. gondii-IgG-reagents; in three cases, clinical symptoms of the disease were found (two with retinochoroiditis and one with retinochoroiditis, obstructive hydrocephalus and calcifications). The incidence rate of the confirmed cases was 0.1 per 1,000 live births. Only five children completed the three-sample serological follow-up. The diagnosis was confirmed in three children, promptly from the first sample.

A total of 30 cases showed clinical abnormalities (Table 3). Optical alterations occurred in 16 cases (7.7\%), with three $(1.4 \%)$ having serious optical lesions (retinochoroiditis), and $13(6.2 \%)$ presenting optical complaints and slight or moderate visual defects, some of which were reported by the families as recent onset. In 10 cases $(4.3 \%)$, there was late neuropsychomotor development, with five of them (2.4\%) presenting convulsions, syncope and irritability. Of those children with clinical abnormalities, 16 were born to mothers with IgM indices between 0.600 and $<1.000$ (Table 3). Most of the mothers did not receive chemoprophylaxis (Table 3). Treatment with spiramycin, sulphadiazine, pyrimethamine and folinic acid was started in two of the three children with serious optical lesions.

\section{DISCUSSION}

The $1.0 \%$ prevalence of pregnant anti- $T$. gondii-IgMreagent women among those attending public health care services points out to the importance of adequately diagnosing and monitoring congenital toxoplasmosis. The infection rate observed in the present study is similar to those in other regions of the country, which ranged between 0.6 and $0.8 \%$, even when different study methods are used. ${ }^{11,16}$ Prospective studies by Spalding et a ${ }^{18}$ (2003) and Varella et al ${ }^{1}$ (2003) in the state of Rio Grande do Sul have reported even higher rates. According to Avelino et $\mathrm{al}^{1}$ (2003), pregnant women are twice as likely to show seroconversion as are non-pregnant women, and seven times more likely if they are adolescents living in environments contaminated by the feces of host animals. Low income and low education increase the risk of seroconversion in women over 30 years of age. Contact with contaminated soil or animals, ingestion of non-commercially preserved food, living in rural areas, and ingestion of raw water are factors that contribute to infection. ${ }^{19}$

There were differences in the number of subjects studied for the several variables analyzed because of the difficulty in obtaining information from records and locating them for interviews.

The majority of women sought early prenatal care, which is a precondition for effective monitoring of maternal-infant health. However, the time required for intervention may be affected by delays in collection of the first sample for the serology test, the follow-up visit for interpretation of the result, the decision to prescribe chemoprophylaxis in each case, and drug availability in the public health system. In monitored assays, maternal infection occurred during a period shortly before the last negative test or at any

Table 3 - Clinical abnormalities in exposed children, mothers' anti-T. gondii IgM indices, and maternal chemoprophylaxis. State of Paraná, Southern Brazil, January 2001 to December 2003.

\begin{tabular}{|c|c|c|c|c|c|c|}
\hline \multirow{2}{*}{$\begin{array}{l}\text { Clinical abnormalities in } \\
\text { exposed children }\end{array}$} & \multicolumn{3}{|c|}{ Mother anti-T. gondii IgM index* } & \multicolumn{2}{|c|}{ Chemoprophylaxis** } & \multirow[t]{2}{*}{ Total } \\
\hline & $>0.600$ to $<1.000$ & $\geq 1.000$ to $<2.000$ & $\geq 2.000$ & Yes & No & \\
\hline Optical alterations & 9 & 2 & 5 & 6 & 10 & 16 \\
\hline Late neuropsychomotor developmen & ent & 3 & 2 & 2 & 8 & 10 \\
\hline Hearing/speech alterations & 2 & 1 & 1 & 1 & 3 & 4 \\
\hline Total & 16 & 6 & 8 & 9 & 21 & 30 \\
\hline
\end{tabular}

${ }^{*} p=0.905 ; * * p=0.746$ 
time up until a short but unknown period before the first positive IgM test. ${ }^{6}$ Therefore, congenital infection remains a concern despite intervention.

The laboratory diagnostic test used with the reagent pregnant women and children exposed was based on IgM and IgG antibodies. They are useful for the initial identification of pregnant women and newborns, ${ }^{11,18}$ and are advocated in the prenatal routine of public health care services in the region. The fact that IgM remains at high levels for many months, ${ }^{9}$ and the difficulty of accessing other laboratory techniques, rendered serodiagnosis of acute toxoplasmosis inadequate. One important aspect is the probable occurrence of false-positive reactions in a certain proportion of the population tested. Testing for anti-T. gondii IgA was not carried out, though recommended in the Protocol for High-Risk Pregnancy. The IgG avidity test was only available to women who could pay for it. The repetition of IgM and IgG tests with two or three samples in some of the women reveals the difficulty in following the protocol recommendations, which suggests new serologies only for pregnant women who are IgM and IgG non-reagent. However, this procedure is inadequate due to the persistence of the $\operatorname{IgM}$ antibodies and the waiting time for results while the infection may be affecting the fetus.

A single IgM and IgG serology test supported the majority of the decisions taken by the doctors regarding therapeutic and prophylactic management. There is controversy over the serological tests used in the diagnosis of acute toxoplasmosis in pregnancy because decisions based on false-positive tests may result in pregnancy interruption and unnecessary treatment. ${ }^{9}$ Several studies have suggested the need for using new serological markers for recent infections, such as $\operatorname{IgA}$, IgE and IgG avidity tests and detection of $T$. gondii by PCR. ${ }^{8,12,18}$ Clinical evidences of toxoplasmosis were not common among the women studied, and cannot always be correlated with reagent serology. $T$. gondii infections may progress to the sub-clinical form in $90 \%$ of cases, presenting nonspecific signs. ${ }^{14,22}$ One important finding was that some women with visual disturbances reported disease recurrence after the birth, indicating the progress of optical lesions, as reported by Gómez-Marín et $\mathrm{al}^{7}$ (2000). The suggestive ultrasonography alterations did not always result in clinical, laboratory and therapeutic follow-up of the unborn children.

Only half of the study pregnant women received treatment, even when complications were suspected. Some studies $^{12,16,22}$ have indicated that therapy can reduce fetal infection in 35 to $60 \%$ of cases. Despite the large number of studies over the last three decades, it is still not known whether prenatal treatment of women with presumed toxoplasmosis reduces congenital transmission of T. gondii.* The prescribed therapy to the studied women was not completed in all of those who were treated. Some of the reasons for treatment discontinuation were drug side effects, high costs, and fetal loss. However, potentially beneficial or harmful effects of treatment on the risk of clinical signs in infected children cannot be excluded. ${ }^{20}$

Pregnant women with higher IgM indices tended to be treated more frequently. Laboratory diagnosis, clinical evidence and ultrasonography exams available were considered enough information for detecting women with suspected infection and providing chemoprophylaxis. The present study showed a lack of consensus among professionals regarding treatment of pregnant women. Even those women who showed low indices of IgM were treated without carrying out other laboratory tests, although such tests are recommended in the State Protocol. One of the most serious problems was the lack of flexibility in the operation of the laboratory examination-revisit-treatment follow-up of the system. The problem of determining fetal infection was reflected in the treatment, as different therapeutic regimens were used. In few cases, a triple regimen (sulphadiazine, pyrimethamine and folinic acid, intercalated with spiramycin) or the continuous use of spiramycin alone until the end of gestation were prescribed both as proposed in the State Protocol. Couto et $\mathrm{al}^{3}$ (2003) emphasized the need to use spiramycin continuously until the end of pregnancy because of its parasitostatic action on $T$. gondii, thereby reducing the risk of vertical transmission.

It was not possible to determine the real prevalence rate of congenital toxoplasmosis due to the small proportion of children who underwent serological follow-up. During their first year of life, almost all children were followed up clinically but few were evaluated for congenital toxoplasmosis. Thirty out of 208 children showed clinical symptoms suggestive of congenital toxoplasmosis, including three confirmed cases of retinochoroiditis, who lacked etiological confirmation and adequate laboratory monitoring. Of the latent complications, retinochoroiditis is the main sequelae of infection in children. Retinochoroiditis can appear years after birth, in adolescence or in adulthood, drastically reducing visual acuity and affecting their quality of life. ${ }^{15,18}$ Segundo et al ${ }^{15}$ (2004) observed retinochoroiditis in 2/805 newborns who had anti-T. gondii IgA, highlighting the importance of clinical and laboratory follow-up. 
In order to reduce the vertical transmission of toxoplasmosis and prevent early and late complications in children, it is essential public health care services monitor the program. In addition to the recommended procedures, there should be confirmatory diagnoses, the integration of the various services providing care to pregnant women and their newborns, and the availability of free therapy. There must be conditions to effectively implement the State Protocol.

The present study showed that the recommendations for monitoring this infection risk are not being systematically observed as some pregnant women with suspect laboratory results were not duly investigated, and some fetuses and newborns went without adequate monitoring for up to 12 months. Confirmed cases of congenital toxoplasmosis were detected only after birth in children with evident clinical abnor-

\section{REFERENCES}

1. Avelino MM, Campos Jr D, Parada JCB, Castro AM. Pregnancy as a risk factor for acute toxoplasmosis seroconversion. Eur J Obstet Gynecol Reprod Biol. 2003;108:19-24.

2. Chemla C, Villena I, Aubert D, Hornoy P, Dupouy D, Leroux $\mathrm{B}$, et al. Preconception seroconversion and maternal seronegativity at delivery do not rule out the risk of congenital toxoplasmosis. Clin Diagn Lab Immnunol. 2002;9:489-90.

3. Couto JCF, Melo RN, Rodrigues MV, Leite JM. Diagnóstico pré-natal e tratamento da toxoplasmose na gestação. Femina. 2003;31:85-90.

4. Falavigna AL, Dias MLG, Casavechia MTG. Prevalência de anticorpos antitoxoplásmicos em trabalhadores de matadouros do município de Maringá, PR. Rev Unimar. 1984;6:175-9.

5. Garcia JL, Navarro IT, Ogawa L, Oliveira RC, Kobilka E. Seroprevalence, epidemiology, and ocular evaluation of human toxoplasmosis in a rural area in Jaguapitã, Paraná, Brazil. Rev Panam Salud Publica. 1999;6(3):157-63

6. Gilbert, RE, Gras L, Wallon M, Peyron F, Ades AE, Dunn DT. Effect of prenatal treatment on mother to child transmission of Toxoplasma gondii: retrospective cohort study of 554 mother-child pairs in Lyon, France. Int J Epidemiol. 2001;30:1303-8.

7. Gómez-Marín JE, Montoya-De-Londono MT, Castano-Osorio JC, Heine FA, Duque AM, Chemla C, et al. Frequency of specific anti-Toxoplasma gondii $\operatorname{IgM}, \operatorname{IgA}$ and IgE in Colombian patients with acute and chronic ocular toxoplasmosis. Mem Inst Oswaldo Cruz. 2000;95:89-94. malities and the presence of IgM. This study pointed out to the need for implementing a surveillance system in Brazil for pregnant women and newborns exposed to T. gondii, as well as other infectious congenital diseases such as syphilis and HIV/AIDS.

\section{ACKNOWLEDGEMENTS}

To the undergraduate medical students Deise Nakazora, Eduardo Roncada and Matheus Jacometo (Universidade Estadual de Maringá) for their participation in data collection; Dr. Norico Misuta and the epidemiology assistant staff at the $15^{\text {th }}$ Division of State Health Department of Paraná: Francisca Pesse, Edna Fugga and .Maria Antonieta Amorin for their support in the research development; Professor Dr. Silvano César da Costa (Universidade Estadual de Londrina) for essential statistical support.
8. Gras L, Gilbert RE, Wallon M, Peyron F, CortinaBorja M. Duration of the response in women acquiring Toxoplasma gondii during pregnancy: implications for clinical practice and cross-sectional incidence studies. Epidemiol Infect. 2004;132:541-8.

9. Kravetz JD, Federman DG. Toxoplasmosis in pregnancy. Am J Med. 2005;118:212-6.

10. Mombro M, Perathoner C, Leone A, Buttafuoco V, Zotti C, Lievre MA, et al. Congenital toxoplasmosis: assessment of risk to newborns in confirmed and uncertain maternal infection. Eur J Pediatr. 2003;162:703-6.

11. Mozzato L, Soibelmann-Procianoy R. Incidência da toxoplasmose congênita no sul do Brasil: estudo prospectivo. Rev Inst Med Trop São Paulo. 2003;45:147-51.

12. Muñoz C, Squierdo C, Parra J, Ginovart G, Margall N. Recommendation for prenatal screening for congenital toxoplasmosis. Eur J Clin Microbiol Infect Dis. 2000;19:324-5.

13. Reiche EMV, Morimoto HK, Farias GN, Hisatsugu KR, Geller L, Gomes AC, et al. Prevalência da tripanossomíase americana, sífilis, toxoplasmose, rubéola, hepatite $B$, hepatite $C$ e da infecção pelo vírus da imunodeficiência humana, avaliada por intermédio de testes sorológicos, em gestantes atendidas no período de 1996 a 1998, no Hospital Universitário Regional Norte do Paraná. (Universidade Estadual de Londrina, Paraná, Brasil). Rev Soc Bras Med Trop. 2000;33:519-27. 
14. Remington JS, McLeod R, Thulliez P, Desmonts G. Toxoplasmosis. In: Remington JS, Klein JO, editors. Infectious diseases in the fetus and newborn infant. $5^{\text {th }}$ ed. Philadelphia: W.B. Saunders Company; 2001. p. 205-346.

15. Sáfadi MAP, Berezin EN, Farhat CK, Carvalho ES. Clinical presentation and follow up of children with congenital toxoplasmosis in Brazil. Braz J Infect Dis. 2003;7:325-31.

16. Segundo GRS, Silva DAO, Mineo JR, Ferreira MS. A comparative study of congenital toxoplasmosis between public and private hospitals from Uberlândia, MG, Brazil. Mem Inst Oswaldo Cruz. 2004;99:13-7.

17. Segundo GRS, Silva DAO, Mineo JR, Ferreira MS Congenital toxoplasmosis in Uberlândia, Minas Gerais, Brazil. J Trop Pediatr. 2004;50:50-3.
18. Spalding SM, Amendoeira MR, Ribeiro LC, Silveira C, Garcia AP, Camillo-Coura L. Estudo prospectivo de gestantes e seus bebês com risco de transmissão de toxoplasmose congênita em município do Rio Grande do Sul. Rev Soc Bras Med Trop. 2003;36:483-91.

19. Spalding SM, Amendoeira MRR, Klein $\mathrm{CH}$, Ribeiro LC. Serological screening and toxoplasmosis exposure factors among pregnant women in south of Brazil. Rev Soc Bras Med Trop. 2005;38:173-7.

20. Thulliez P. Efficacy of prenatal treatment for toxoplasmosis: a possibility that cannot be ruled out. Int J Epidemiol. 2001;30:1315-6.

21. Varella IS, Wagner MB, Darela AC, Nunes LM, Müller RW. Prevalência da soropositividade para toxoplasmose em gestantes. J Pediatr. 2003;79:69-74.

22. Wong SY, Remington JS. Toxoplasmosis in pregnancy. Clin Infect Dis. 1994;18:853-62. 